\title{
Leadership In Learning And Teaching In Higher Education: Perspectives Of Academics In Non-Formal Leadership Roles
}

\author{
Anne Hofmeyer, University of South Australia, Australia \\ Brenda Helen Sheingold, The George Washington University, USA \\ Hester C. Klopper, North-West University (Potchefstroom Campus), South Africa \\ Jane Warland, University of South Australia, Australia
}

\begin{abstract}
Developing leaders and leadership are key factors to improve learning and teaching in higher education. Despite the abundance of literature concerning developing formal leadership, fewer studies have been conducted with academics in non-formal leadership roles that focus on how they develop their leadership in learning and teaching. Publication and funding metrics are evidence of leadership and success in research. Metrics in learning and teaching exist, but are less well accepted and valued. We undertook a qualitative descriptive study to examine how academics in non-formal leadership roles at an Australian university understood leadership and described their leadership in teaching. Following ethical approval, eight participants were interviewed using a semi-structured format. Thematic analysis revealed four themes: leadership is the ability to influence direction; all about the culture; becoming visible and speaking up; and learning leadership together. Participants said leading teaching teams effectively and influencing quality learning experiences for students and colleagues is 'evidence' of leadership in learning and teaching. Some said a few research colleagues and formal leaders did not accept such 'evidence' and continued to favour leadership of research teams. This paper contributes new strategies as possible ways forward to facilitate cultural change in higher education institutions that include: a need for formal leaders and academics to reach agreement about evidence of effective leadership in learning and teaching; academics sharing innovations to effectively lead teaching teams and to promote quality teaching experiences for students; and mentoring colleagues in learning and teaching.
\end{abstract}

Keywords: Leadership; Higher Education; Academia; Teaching; Learning; Faculty Mentoring; Scholarship of Teaching; Nursing

\section{INTRODUCTION}

eadership models and traits required by leaders to effectively lead organisations in this era of increased efficiency and accountability continue to be the subject of considerable research and discussion (Avolio, Gardner, Walumbwa, Luthans \& May, 2004; Boyatzis, Passarelli, Koenig, et al., 2012; Cuddy, Kohut \& Neffinger, 2013; Dasborough, 2006; Einarsen, Aasland \& Skogstad, 2007; Johnson, 2002; McKee $\&$ Massimilian, 2006). Similarly in higher education, studies of effective formal leadership and management traits confirm that leaders and leadership is crucial to improving the governance, learning, teaching, relevance and success of higher education institutions (Bolden, Petrov, Gosling \& Bryman, 2009; Bryman, 2007, 2009, Middlehurst, 2008; Parrish, 2013; Ramsden, 1998; Scott, Coates \& Anderson, 2008, 2010). Despite the extensive literature on formal leadership positions in higher education, little is known about how academics develop and enact leadership in learning and teaching that are employed in non-formal leadership positions (Juntrasook, Nairn, Bond \& SpronkenSmith, 2013; Middlehurst, 2008). This presents difficulties for academics so it is therefore timely to consider the 
means to develop leadership in learning and teaching and identify performance-based indicators that will be acceptable evidence for reviews, promotion and tenure.

In this study, we sought to understand how academics not employed in formal leadership roles understood themselves as leaders in learning and teaching and developed their scholarship. Before we present our findings, we provide a brief overview of leadership in general, in the higher education sector, and conclude with leadership in learning and teaching.

\section{REVIEW OF THE LITERATURE}

\section{Leadership}

Leadership can be defined in terms of traits, characteristics and behaviours that focus on a clear vision, action, modelling the way, ethical relationships, congruence, trustworthiness and collaboration (Avolio et al., 2004). The nature of relationships with leaders influences job satisfaction, turnover, positive relationships and wellbeing of followers and organisational productivity (Avolio et al., 2004; Boyatzis et al., 2012). Not surprisingly, the behaviour of leaders triggers an emotional response in those they lead and affects their performance (Dasborough, 2006). 'Resonant leaders' effectively manage their emotions and inspire followers to work in complex and changing environments (McKee \& Massimilian, 2006). Leaders exhibiting resonant traits are trusted, have empathy, insight and realise their emotions and stress influences others (Dasborough, 2006). These resonate traits closely align with emotional intelligence which has been linked with effective academic leadership (Parrish, 2013). As Johnson (2002) explains, 'resonant leaders rely on coaching instead of coercion, build harmony, and value input and participation' (p. 2). Individuals working with resonant leaders understand what they are being asked to do and why, and are committed to collective goals. Conversely, a leader exhibiting dissonant traits uses command and coercive practices to persuade staff to work, often with little support or resources. Dissonant behaviours include micromanagement, betrayal and insensitivity (Frost 2004) that undermines team effectiveness (Johnson, 2002, p. 2). Destructive, callous or abusive leadership has negative consequences that affect the wellbeing and performance of individuals and organisations (Boyatzis et al., 2012; Einarsen et al., 2007). Such destructive behaviours and incivility 'create toxic emotions' that negatively affect the wellbeing of individuals and team functioning (Boyatzis et al., 2012, p. 261; Clark et al., 2012).

\section{Leadership in Higher Education}

Leadership and management have been proposed as two different, but necessary, elements of formal academic governance and individuals in those roles influence the culture and learning and teaching in distinct ways (Marshall et al., 2011, Ramsden, 1998). Individuals with management responsibilities focus on administrative rules, tasks and functions to ensure the managerial goals of the organisation are met effectively (Ramsden, 1998). In a national study, it was shown that effective formal leaders exhibit characteristics such as self-awareness, current knowledge, competence and the ability to influence success in higher education (Scott et al., 2008). Likewise, Bryman (2007, p. 697) analysed international literature and identified 13 forms of leader behaviour associated with departmental effectiveness and concluded that leaders should focus on 'vision, integrity, consideration, and sense of direction' (p. 697). Individuals in formal leadership positions who are effective demonstrate emotional intelligence and a consultative and collaborative style that supports academics to perform effectively (Bryman, 2007, 2009; Parrish, 2013).

The recent interest in the higher education literature about leadership is in response to calls for more relevant democratic cultures and less hierarchical models of leadership (Jones Lefoe, Harvey \& Ryland, 2012). There is an emergent view that leadership is everyone's responsibility (Bolden, Petrov \& Gosling, 2008). To that end, distributed and collective leadership styles have been proposed as a means for academics to develop shared responsibility in changing higher education cultures (Jones et al., 2012; Bolden et al., 2008; Jones, et al., 2012; Middlehurst, 2008). The focus of distributive leadership is on 'collective collaboration rather than individual power and control' to build leadership capacity in learning and teaching (Jones et al., 2012 p. 67). There are contested meanings of leadership in higher education that need to be understood and considered in these debates, namely: 'leadership as position; leadership as performance; leadership as practice; and leadership as professional role model' 
(Juntrasook, 2014, p. 22-27). Notably, successful cultural change in higher education does not just occur-it is led effectively and understood as a complex learning and unlearning process for all, rather than simply an event (Scott et al., 2008).

\section{Leadership in Learning and Teaching}

Leadership is urgently needed at all levels of the organisation (Marron \& Cunniff, 2014). But Quinlan (2014, p. 32) asserts that research endeavours have mostly overlooked the topic of 'leadership of teaching (by explicitly including knowledge and evidence related to teaching and learning) for student learning'. Many academics develop effective learning and teaching experiences for students (as curriculum writers and innovative teachers) that also contributes value for colleagues and institutions (Raven 1990). However, these activities are seldom the focus of research or valued as performance-based indicators of leadership in learning and teaching by supervisors or research colleagues. Not surprisingly, debates persist about the lack of parity in status between teaching and research (Nunn \& Pillay 2014). Notably, a research performance-based indicator called the h-index was developed in 2005 (Hirsch 2005). This development meant that research performance became clear to evaluate using this citation index, but this ease led to research being 'weighted heaviest' in evaluations (Pillay 2013, p. 2598). Evaluation of teaching leadership effectiveness has largely focused on an individual's teaching philosophy and pedagogical approach, classroom activities, teaching curriculum, innovative materials and evaluations from students and colleagues (Nunn \& Pillay 2014). But the assessment of quality in teaching remains elusive (Glassick 2000).

It is therefore timely to consider the means to implement collaborative models of leadership to promote learning and teaching and to clearly articulate incentives, rewards and performance-based expectations for promotion and tenure. What remains poorly understood is the practise of leadership in learning and teaching by academics in non-formal leadership roles. We sought to contribute to the scant literature by examining how academics understand themselves as leaders in their learning and teaching practise, how they developed their capacity, and how they identified achievement in their everyday work cultures.

\section{METHODS}

The aim of this qualitative descriptive study was to investigate how academics not employed in formal leadership positions understand, describe and develop their leadership in ways consistent with advancing and improving learning and teaching in higher education. Semi-structured interviews were considered the most suitable data collection method to generate qualitative information to facilitate this exploration (Sandelowski, 2010).

\section{Participants}

We recruited eight academics not employed in formal leadership roles at an Australian university in the Schools of Health Sciences, Pharmacy and Medical Sciences, and Nursing and Midwifery. Participants included seven females and one male, with four participants aged 31 to 39 (L1; L2; L3; L4) and four participants aged 40 years plus $(\mathrm{C} 1 ; \mathrm{C} 2 ; \mathrm{C} 3 ; \mathrm{C} 4)$. Their careers in higher education spanned from 5 years to 24 years with an average of 10.5 years. All were Masters prepared with 6 participants (75\%) having a PhD.

\section{Data Collection}

Recruitment, data collection and analysis occurred concurrently until emerging themes were repeated (Schneider et al., 2013). Data were collected between January and March 2013. Participants gave written consent to be interviewed and recorded (Schneider et al., 2013). The study was approved by the institutional Human Research Ethics Committee. No identifying features were used in the manuscript with pseudonyms attributed to the words of individual participants. Interviews lasted 25 to 40 minutes and were conducted in person $(n=7)$ or by telephone $(\mathrm{n}=1)$ according to the preference of the participant. A set of questions was used to guide the interviews:

- Can you talk about your understanding of the concept of leadership; what does leadership mean to you; what do you think makes a good leader?

$\circ \quad$ What do you consider is the difference between a leader and a manager? 
- Can you talk about your leadership practice; have you thought about this - what is expected of you in your teaching role; how do you [influence] bring about change in your practice; can you provide examples of your achievements as a leader of learning and teaching with colleagues and/or students?

- Can you talk about how you developed your leadership; have you undertaken leadership learning to develop your career? If yes: what did you learn to enable you to improve your teaching role; what type of culture hinders or encourages your leadership development; what resources enhance your effective leadership development.

\section{Data Analysis}

Recordings were transcribed by a confidential transcribing service, then checked for accuracy and anonymized. Analysis was a systematic, iterative process involving active reflexivity to organise the data into meaningful categories and produce credible explanations (Ruona, 2005; Sandelowski, 2010; Schneider et al., 2013). Data were analysed thematically to understand participants' meanings and analyse similar and different patterns (Ruona, 2005, pp. 240-245). Two researchers (AH, JW) independently analysed the transcripts and made summary notes including key words, phrases and verbatim sections to illustrate meaning. They then met to discuss and compare their notes and the themes were determined by consensus (Schneider et al., 2013). The researchers explored how the themes were connected to each other and to the literature. These strategies supported dependability and credibility of the study. Authenticity and confirmability is established through the use of verbatim statements from participants to support findings. The rigorous data analysis process and the researchers' expertise and audit trail of decisions ensured trustworthiness of the data (Guba \& Lincoln, 1994; Ruona, 2005).

\section{FINDINGS}

Findings are presented in four themes: leadership is the ability to influence direction; all about the culture; becoming visible and speaking up; and learning leadership together.

\section{Leadership is the Ability to Influence Direction}

When asked about the concept of leadership, most participants began by discussing their views about resonant characteristics of a formal leader, although we did not specifically ask about formal leaders. Some described leadership as 'action' and believed that the manner in which a leader relates with others directly influences the organisation's culture. All participants used the metaphor of movement and having a clear direction and vision for the team: leadership is the ability to influence direction and keep momentum going (L4). Another participant explained:

Movement towards change, better situation, create a cohesive culture. Leadership brings people together, lead people into a certain direction (L2)

Participants said leaders needed: effective communication abilities (L3; C4), to be trusted and show respect for workers $(\mathrm{C} 2)$. One participant commented that leaders need the: ability to understand complex aspects of situations and relate them to others in succinct ways and to motivate people (L3). Leaders need to understand how the organisation works and have: institutional credibility (L3) be aware of power relations (C1), know their staff (C3) and know how to lead staff and the organisation towards a common vision. Specifically:

Formal leaders must have a bigger picture. If they're looking at small details, it means they're not looking after the bigger picture of where we're heading. Leaders have to be able to make difficult decisions when there can't be a consensus (L1)

All participants said leaders need a global view and be outward looking and strategic. One participant stated: leaders ask the right questions that go deeper (L2). A participant explained: leadership is about wanting to champion an interest and bring other people in towards supporting that interest (L1). Thus, inclusion and encouragement underpin effective relationships between leaders and others to engage in a common goal. Another participant understood that leaders do not have to be in formal leadership roles: You can be a leader without being anybody's 
boss, so you can be a peer, but can be the leader of a group (L3). All emphasised that successful leaders invest time in getting to know the people they lead and help everyone to focus $(\mathrm{C} 4)$. Developing relationships is the first step in developing and inspiring others: A good leader promotes others at the same time, so it's not just all about them (C1).

Most participants noted an overlap between leading and managing in higher education. Most said there is a managerial component to leadership: ideally a manager is also a decent leader (L3). A manager was seen as: organising and categorising (L2). Another suggested: people confuse leadership and management (C1) and distinguish by saying:

A leader is someone that people jump ship to follow. A manager can be a good leader and a leader can be a manager, but a manager is a job (L3).

The leader is not a job. A good manager is not necessarily a good leader (C1)

Another participant stated: A lot of us find "power" a dirty word-it's uncomfortable. A good leader needs to be aware of power relations, and not exert power to put others down $(\mathrm{C} 1)$. Other participants said managers deal with: functionality (L4) and coordinating the day-to-day administration of policies and procedures of the organisation such as performance reviews, organising resources and staff allocation (C1; L2; C4). Others stated that a manager does not mentor staff (C2), but requires: skills to solve grievances (L3). Others said managers have an introspective focus (L1). Whereas leaders are expected to: look outside the organisation at the direction of industry, and be involved in strategic planning (L1). Managers have the power to direct staff according to organisational policies and rules to achieve outcomes (C3). Although leaders also direct their staff, other participants thought the interactions were more relational because leaders use insight into people's behaviour and characteristics $(\mathrm{C} 3)$.

\section{All About the Culture}

Most participants perceived that formal leaders in manager positions influenced the workplace culture, and controlled opportunities for leadership development in teaching and incentives. Participants stated they experienced indifference, micromanagement, poor decision making and invisibility in their workplace culture (L2) which did not foster a trusting, cooperative culture. The manner in which formal leaders engage in the culture was seen to mostly hinder relationships. A participant stated: Toxic leaders can't make decisions, or make too many decisions that are not what a leader should be taking care of (L1). Another stated: If there are no complaints, they don't care. So it's basically indifference. A lot of people are into micromanagement, not my style (C3). Being watched is not a productive work culture (L4) and reduces the confidence necessary to enact leadership, and no incentive to work as a team $(\mathrm{L} 1)$.

Some participants expressed frustration about senior management's bias towards research (C3), saying that teaching, and those who teach are disenfranchised and: They value research over everything else (L1). Most perceived that examples of everyday leadership in teaching were not valued or recognised as legitimate achievements by individuals in formal leadership roles or research colleagues. A few participants discussed being criticised by research colleagues for time invested in teaching (such as in course coordination, leading teams and mentoring students) and were advised to spend less time on teaching and more time improving their research metrics. Unless you publish it doesn't matter (L1). Some participants said it has been hard to find professors who weren't territorial and generous in terms of fostering and mentoring others in developing their teaching research (C3). Some felt marginalised and frustrated because teaching leadership and metrics of success continue to be ill defined and mentors were few:

Research professors say, 'I like your idea-might not be able to put a lot of time into this project, but happy to have my name on because it helps you get your foot in the door'. But in education research, we don't have leaders because you're not promoted in the first place. Everybody knows academics can be promoted entirely on research and have a terrible teaching metric (L1). 
Notably, a lack of leadership in teaching teams can result in no decisions being made, or decisions that are 'agreed' at meetings are later not followed by all team members. One said this resulted in poor team morale, haphazard functioning and inconsistent teaching outcomes (L1). Most reported feeling sad and alienated in their work culture, but persisted by adopting strategies to thrive such as connecting with people who are like-minded and who have similar goals (C3). They could only influence change in their sub-culture, as one participant said:

If there's no culture of discussion of different ideas or ways to do anything then that doesn't support difference. If formal leaders aren't interested in what's going on, except at their own level, then that doesn't help the culture. Between formal leaders and the informal leadership, there's a complete disconnect. So culture is important (C3).

Some participants attended professional development sessions for leadership, but said there was no support in the culture or from formal leaders to build on these learning opportunities, so they felt their leadership development was going nowhere and resources to run these sessions were wasted. They relied on: chance and hope that change might occur. So one tends to lose passion, drive, it could be better (C3).

\section{Becoming Visible and Speaking Up}

This theme illustrated participants' aspiration to lead individuals beside or below them to foster change and growth. Initially in the interviews, most participants said they did not consider themselves as leaders, or what they did as leadership in learning and teaching. Some had difficulty providing examples of their leadership in teaching because they had not previously thought about it. But one example provided was leadership in curriculum design (C1), although the participant noted: it is not feminine or Australian to promote oneself as a leader (C1). A few stated they had been: forced to think about it (L1) for promotion and grant applications (L4). But, most participants said examples of success were hard to identify or achieve because there are few opportunities or clarity about metrics. Success is exemplified by one participant as:

Receiving student-nominated awards, being the go-to person, being knowledgeable about the workplace, retaining casual tutors on your team, coordinating large courses, leading large teaching teams of mostly casual tutors (L1)

Another example of success was receiving an invitation to chair an external professional committee that provided valuable: opportunities to network with influential leaders from other universities and government organisations (L4). A few linked their success with the growth and success of others with leadership. One encouraged students with potential to apply for scholarships: If I don't say something, they might miss that opportunity (L1). Another said: It means looking out for those alongside you, below, or even above you (L2). Some provided examples of speaking up to promote their colleagues' achievements in learning and teaching to those holding formal leadership roles. They believed acknowledgement from others is more likely to be influential than self-promotion, and that it is time for everyone to make that change, as one participant described:

We have the ability to say to people above us, this person is terrific-they care about the students and organisation. That's the kind of influence I'm working on (L1)

Most participants said everybody had a responsibility to be visible and influence the culture through their own leadership values and action. They said that everyone needed to speak up, be persistent and promote their own and others' teaching success in order to increase their visibility with formal leaders. Most participants emphasised visibility: move from being out of sight to being visible (L2) as a key strategy to lead change. A participant believed that recognition by formal leaders is linked to visibility and clarity about why you are leading: If the boss doesn't see that clearly then don't become upset if there's no recognition (L2).

\section{Learning Leadership Together}

When asked what they needed to learn about leadership the participants indicated they wanted to develop a personal awareness of their leadership style and most identified mentoring as a key strategy. A participant said: 
connecting with others is really important. We have a mentoring role with others (L1). Some participants wanted to learn how to communicate more effectively in teaching teams, manage difficult situations, deal with conflict, and manage workload stress and time (C4). Many wondered how to find a mentor with the right qualities who could provide support related to leadership development in teaching. Others said they had made a conscious decision to lead because they wanted to accomplish something better, so would be open to any strategies. Some discussed strategies to enhance retention of casual teaching tutors in their teaching teams and promote student satisfaction. But a participant noted: if you don't have the professional and personal respect of peers it's not going to work (C2). A few participants said a strategy that proved successful for them was to network with like-minded people who were willing to mentor others in mini-cultures (C3). Specifically: I go to my mentors when the need arises (L2).

When asked how they learned leadership skills in teaching, the participants indicated that they read widely, watched respected colleagues, and actively sought formal or informal mentoring opportunities with experienced academics. All said that mentors must be trustworthy, experienced, competent, and honest and be a person who gently listens and asks the right questions (L2). A mentor should be: someone who shakes you up a bit, or gets you to think or to hang on (C1). A few participants noted reluctance by some academics to get involved because mentoring is perceived to be time consuming. Another explained: You need to discern the people who are important to your leadership development and contact them in a respectful way $(\mathrm{C} 2)$. Others discussed mentoring as an example of their own leadership and felt satisfied when supporting students and colleagues to strive towards their potential. Although some did not conceptualise their mentoring of others as leadership, they persevered in mentoring relationships because it was how they wanted to be for others: it's a two way learning process and we have a responsibility to give back $(\mathrm{C} 2)$.

\section{DISCUSSION}

Higher education faces complex managerial controls and the obligation to demonstrate relevance, accountability and benefit for society (Scott et al., 2008). Academics must be better prepared to provide quality learning and teaching outcomes, collaborate to identify and research real world problems, and lead the practical application of new knowledge to solve problems. But such change does not occur spontaneously in higher education - it must be led (Bryman, 2007; Scott et al., 2008, 2010). Much of the previous research has examined the concept of formal leadership in higher education governance. Few studies have examined how academics in non-formal leadership roles understand themselves as leaders in teaching and learning in their everyday work environments to promote student experiences. In this study, participants placed importance on developing their leadership in learning and teaching, even when they perceived there was little support or recognition of achievement by formal leaders in the work culture. When discussing the concept of leadership, the participants discussed the preferred traits of leaders that closely aligned with resonant characteristics in the literature (Johnson, 2002; McKee \& Massimilian, 2006). How individuals with formal leadership responsibilities relate to and understand their staff was seen to influence work culture and productivity, as with other studies (Bryman, 2007). Some individuals were seen to have a clear sense of direction and vision and the capacity to bring people together and influence their movement towards change and collective goal achievement. This finding is consistent with literature that identifies the importance of integrity and collaboration for leadership effectiveness (Avolio et al., 2004; Boyatzis et al., 2012; Cuddy et al., 2013). The formal organisational roles of leadership and management were perceived by participants as entwined and complementary to ensure the governance and administrative functions were achieved. Managers were considered to be inward focused to ensure the rules and policies were followed by staff, and to manage grievances. Leaders needed to be outward looking and have institutional credibility in order to create positive work environments for staff. The literature confirms similar views (Bryman, 2007; Parrish, 2013; Ramsden, 1998).

In the context of higher education, the participants stated that individuals with formal leadership responsibilities had significant influence over the culture and the power to determine how teaching workloads were distributed, adjusted and rewarded. This view is supported in the literature (Bryman, 2007). The style of some formal leaders was described by participants as dictatorial, which directly influenced relationships with staff and the workplace culture. This perception relates to calls in the literature for less hierarchical models of leadership in higher education, such as distributed, collaborative models (Jones et al., 2012). Most perceived the incentives, rewards and evidence of success for promotion and performance reviews were abundant for researchers. In our study, participants said they perceived a lack of parity in their status as compared with research colleagues. 
Leadership in learning and teaching matters for promotion and student experience, but there is limited incentive, recognition or legitimacy in the culture to develop leadership skills in this area of academic scholarship. Participants noted that mentors in research were plentiful, but few had been promoted due to teaching metrics; therefore, a paucity of leaders existed to mentor leadership development in learning and teaching. Some were dismayed by feedback from formal leaders and colleagues to prioritise their research outputs to ensure career success. Thus, the advice was to limit time spent on teaching leadership activities, such as coordinating large teaching teams and mentoring students, colleagues and casual tutors. This message that research is the top priority in higher education undermines and disenfranchises individuals committed to leadership in learning and teaching for students. This view is supported by Hemer (2014, p. 488) who reported a lecturer in his study stated that "he felt like a 'second class citizen' in placing high priority on his teaching". Clearly this view is a stumbling block for some academics (Glassick 2000). While a diversity of teaching activities is expected, participants noted there are few measures of success comparable to publication and funding metrics. As found in other studies (Boyatzis et al., 2012; Einarsen et al., 2007; Frost 2004; Johnson, 2002), some participants described toxic cultures that failed to foster collegiality and featured indifference, mistrust and micromanagement. Such cultures result in inconsistent teaching, poor morale in teaching teams, and few incentives for academics to step up and become visible and lead in teaching and learning activities. Although some participants did not consider themselves leaders and struggled to articulate their learning and teaching contributions in terms of leadership, they persevered in their work because they believed collegiality mattered. This reflected a commitment to collaborative leadership with peers, but relationships with formal leaders was less clear. Becoming visible and speaking up about one's own and others' achievements in teaching was strongly promoted as a key strategy for success and recognition by formal leaders. Being the 'go-to person' who connected colleagues and students with opportunities to influence their learning was an indicator of leading (Raven, 1990).

Participants reflected on what they needed to learn and how they planned to do it. They described diverse learning needs, such as coping with high teaching workloads, leading large teaching teams, and managing difficult situations with students and team members. Developing effective ad hoc mentoring relationships and links with likeminded colleagues who have greater experience was a common strategy to improve performance and career success, as confirmed in the literature (Cleary et al., 2013). Being connected in mini-cultures provided informal, valuable opportunities to be mentored and to learn from others in respectful networks. A number of studies have stressed the importance of trustworthy connections in learning leadership skills to enhance productivity (Del Favero, 2003; Gopee 2002). Identifying a specific learning goal and then approaching a competent colleague to collaborate in a mentoring relationship is a strategy to build resilience, competence and leadership.

\section{IMPLICATIONS}

There is a gap between subcultures that value leadership in learning and teaching, mentoring colleagues and students, and celebrating everyday teaching achievements; fostering the scholarship of teaching; and cultures that fail to clarify metrics or offer clear incentives and rewards. It is necessary to bridge this gap by fostering urgent cultural change that supports academics to build their leadership in teaching to provide quality experiences for students, and contribute to societal expectations of higher education. The results of this study call for proactive, collaborative efforts between all academics to develop processes that support and sustain leadership development and recognition in learning and teaching. It is timely to adopt responsive leadership models and implement relevant ideas to enhance collaborative leadership development for all (Bryman, 2007, 2009; Jones et al., 2012; Parrish, 2013; Scott et al., 2008). There are agreed training pathways to build effective leadership skills and capability in research and metrics to measure success. Although evidence of leadership in learning and teaching is required in performance, promotion and tenure applications, training pathways and metrics to measure success are less well formulated and accepted. Individuals in formal leadership roles need to facilitate opportunities for all their staff to develop leadership skills and capabilities in learning and teaching (Bolden et al., 2008). Strategic approaches to change current perceptions, improve acceptance and valuing, and build leadership capacity and success in learning and teaching must be embedded in the higher education culture. We propose the following guiding principles to facilitate overdue cultural change, namely: 
- $\quad$ Leadership development must be available for all academics in higher education;

- All academics have a moral responsibility to cultivate civility in the workplace, foster inclusive cultures and networks to mentor and affirm colleagues and students;

- Collaborative engagement between all academics to identify evidence and metrics of leadership success in learning and teaching and developmental pathways and incentives;

- Coordinating large courses, leading teaching teams and influencing quality learning experiences for students and colleagues is evidence of academic leadership in learning and teaching, and metrics of success.

\section{LIMITATIONS}

The findings need to be considered in light of several limitations. It is possible the findings may have been influenced by the sampling strategy used and the number of participants. Participants were all employed at the same university and recruited via university notices. Therefore, the study may have attracted academics with a preexisting interest in the topic. Additionally, these findings may not be generalizable because the extent of the issue in higher education globally has not been widely studied, and thus, there is a paucity of available research.

\section{CONCLUSION}

Leadership in teaching and learning by academics in non-formal roles could be more widely promoted and rewarded in higher education. In this study, we have found that all academics in higher education need to consider adopting collaborative leadership characteristics that are primed to create new cultures to support quality leadership in learning and teaching scholarship. Innovative higher education institutions will value all forms of scholarship, embrace a diversity of views, and cultivate civility and cooperative networks. This cultural change will require courageous leadership by academics in formal and non-formal roles, a coordinated approach, incentives to value quality in teaching, and governance processes to recognise and reward teaching as a career path. Such strategic change has the potential to improve the opportunities, satisfaction and outcomes for current and future generations of academics and students in higher education.

\section{ACKNOWLEDGEMENTS}

We would like to sincerely thank the blind peer reviewers and academics who shared their insights and experiences and gave generously of their time to participate in this study.

\section{DECLARATION OF CONFLICTING INTERESTS}

The authors declare no potential conflicts of interest with respect to the research, authorship, and/or submission of this article.

\section{FUNDING}

The authors received no financial support for the research, or authorship.

\section{AUTHOR INFORMATION}

\section{Anne Hofmeyer PhD, MPHC, RN, MACN}

Dr Anne Hofmeyer PhD, RN, MACN is Senior Lecturer, School of Nursing \& Midwifery, University of South Australia. She received her Doctorate from Flinders University, Australia and completed her Post-Doctoral work at the University of Alberta. Dr Hofmeyer served as Associate Professor at the Australian Catholic University. She teaches research in undergraduate and graduate programs. Her research interests focus on leadership, values, compassion and how social capital can foster networks of trust, inclusion and cooperation in higher education and health systems. She has diverse disciplinary and interdisciplinary research collaborations in South Africa, Australia, USA, UK and Canada; in sum attracting over $\$ 1.7$ million in collaborative/sole funding. Her publication record 
includes refereed journals, conference papers, books and book chapters. She was appointed to the Research Scholarship and Advisory Council for The Honor Society of Nursing, Sigma Theta Tau International (2012-2015). Email: anne.hofmeyer@unisa.edu.au (contact author)

\section{Brenda Helen Sheingold, PhD, RN, FNAP}

Brenda Helen Sheingold, PhD, RN, FNAP, is the Director of Healthcare Quality Graduate Programs and Assistant Professor at George Washington School of Nursing. She received the GW Chapter of Sigma Theta Tau Research Award in 2013 \& 2014 for her work to identify Best Practices in Nurse-led Patient-Centered Medical Homes and the GW Honor Society Excellence in Research Award in 2009 and for her work on measuring social capital in the nursing workforce. In 2012, she was inducted as a Fellow and Distinguished Scholar in the National Academies of Practice. Email: bsheingo@email.gwu.edu

\section{Hester C. Klopper PhD, MBA, FANSA}

Professional registration: RN; RM; RCHN; RPN; RNE; RNM

Hester Klopper is an international academic and professional leader with extensive international networks in global health, public health, policy development, nursing and health care. She is the Chief Executive Officer of FUNDISA (Forum for University Nursing Deans in SA) and the President of Sigma Theta Tau International (2013-2015) (She is the first person outside of North America to be elected to the position of President of STTI). Prior to this position, she was the Dean of the Faculty of Community and Health Sciences, University of the Western Cape, South Africa, where she continues to hold a full professor appointment. In addition, she holds a professor position with INSINQ, a research focus area, based at North-West University (Potchefstroom Campus). She holds a Master's degree (1992) and $\mathrm{PhD}$ (1994) from University of Johannesburg and a MBA (2002) from Luton University in the UK. As a scholar her research programme focuses on positive practice environments, patient safety and quality improvement. A continued interest is global health and the role nurses play in policy influence and strengthening health systems. She has been successful in securing funding for her work over the past decade of more than 50 million ZAR. Embedded in her work, is the focus on leadership development and capacity development of young scientists. She coordinates the national programme, the PLUME programme, funded by the National Research Foundation (NRF), to support the development of research programmes of university nursing department and post-doctoral candidates. Hester has been the supervisor of more than $25 \mathrm{PhD}$ students and 45+ master's students; she has published 60+ peer reviewed publications, and presented her research and scholarly work at more than 100 international conferences. She is a Fellow of the Academy of Nursing of South Africa (FANSA), an inductee into the Hall of Fame for Excellence in Nursing Research (FUNDISA) and most recently, a member of the Institute of Directors of South Africa (IODSA). Email: klopperhc@gmail.com

\section{Jane Warland RN, RM, DipAppl Sc (nurs), PhD, Grad Cert Ed (Uni Teach)}

Dr. Jane Warland is a Senior Lecturer in Nursing and Midwifery at the University of South Australia (UniSA). She worked as a nurse midwife from 1988-2007. She gained her PhD in medicine/health sciences from the University of Adelaide in 2007. She then joined the academic staff in the School of Nursing and Midwifery in Feb 2008 and achieved promotion to Senior Lecturer in 2011. Jane's program of research is STELLAR (Stillbirth Teaching Epidemiology Loss Learning Awareness and Risks). Her research program website is http://stellarresearch.weebly.com/ Jane has a track record in research using qualitative, quantitative and mixed methods. She is a published author for several books, book chapters and more than 40 peer reviewed journal articles and has presented her research at numerous national and international conferences. Email: jane.warland@unisa.edu.au

\section{REFERENCES}

Avolio, B. J., Gardner, W. L., Walumbwa, F. O., Luthans, F. \& May, D. (2004). Unlocking the mask: A look at the process by which authentic leaders impact follower attitudes and behaviors. Leadership Quarterly. 15(6) $801-823$.

Bolden, R., Petrov, G. \& Gosling, J. (2008). Developing collective leadership in higher education. Research and Development Series, Leadership Foundation for Higher Education: UK.

Bolden, R., Petrov, G., Gosling, J. \& Bryman, A. (2009). Leadership in higher education: Facts, fictions and futures: Introduction to the special issue. Leadership. 5(3) 291-298. 
Bryman, A. (2007). Effective leadership in higher education: A literature review. Studies in Higher Education. 32(6) 693-710.

Bryman, A. (2009). Effective leadership in Higher Education: Final Report. Leadership Foundation for Higher Education: UK.

Boyatzis, R. E., Passarelli, A. M., Koenig, K., Lowe, M., Matthew, B., Stoller, J. K. \& Phillips, M. (2012). Examination of the neural substrates activated in memories of experiences with resonant and dissonant leaders. Leadership Quarterly. 23(2) 259-272.

Clark, C., Olender, L., Kenski, D., \& Cardoni, C. (2013). Exploring and Addressing Faculty-to-Faculty Incivility: A National Perspective and Literature Review. Journal of Nursing Education. 52(4) 1-8.

Cleary, M., Horsfall, J. \& Walter, G. (2013). Academic careers and promotion: Character and conduct deserve greater emphasis. Journal of Advanced Nursing. 69(8) 1675-1677.

Cuddy, A., Kohut, M. \& Neffinger, J. (2013). Connect, then lead. Harvard Business Review, July-August, 55-61.

Dasborough, M. T. (2006). Cognitive asymmetry in employee emotional reactions to leadership behaviors. Leadership Quarterly. 79(2) 163-178.

Del Favero, M. (2003). Faculty-administrator relationships as integral to high performing governance systems. American Behavioural Scientist. 46(7) 902-922.

Einarsen, S., Aasland, M. S., \& Skogstad, A. (2007). Destructive leadership behaviour: A definition and conceptual model. Leadership Quarterly. 18(3) 207-216.

Frost, P. J. (2004). Handling toxic emotions: New challenges for leaders and their organization. Organizational Dynamics. 33, 111-127.

Glassick, C.E. (2000). Boyer's Expanded Definitions of Scholarship, the Standards for Assessing Scholarship, and the Elusiveness of the Scholarship of Teaching. Academic Medicine. 75(9) 877-880.

Gopee, N. (2002). Human and social capital as facilitators of lifelong learning in nursing. Nurse Education Today. $22(8)$ 608-616.

Guba, E.G. \& Lincoln, Y.S. (1994). Competing paradigms in qualitative research. In N.K. Denzin \& Y.S. Lincoln (Eds.), Handbook of qualitative research. 105-117 Sage.

Hemer S.R. (2014). Finding time for quality teaching: an ethnographic study of academic workloads in the social sciences and their impact on teaching practices, Higher Education Research \& Development. 33(3) 483495.

Hirsch, J.E. (2005). An index to quantify an individual's scientific research output. Proceedings of the National Academy of Sciences of the USA. 12(6) 16569-16572

Johnson, C. (2002). Evaluating the impact of emotional intelligence on leadership performance. International Leadership Association Conference, Seattle, WA.

Jones, S. Lefoe, G. Harvey, M. \& Ryland, K. (2012). Distributed leadership: A collaborative framework for academics, executives and professionals in higher education. Journal of Higher Education Policy and Management. 34(1) 67-78.

Juntrasook, A., Nairn, K., Bond, C. \& Spronken-Smith, R. (2013). Unpacking the narrative of non-positional leadership in academia: Hero and/or victim? Higher Education Research \& Development. 32(2) 201-213.

Juntrasook A. (2014). 'You do not have to be the boss to be a leader': Contested meanings of leadership in higher education, Higher Education Research \& Development. 33(1) 19-31.

Marron, J.M. \& Cunniff, D. (2014). What Is An Innovative Educational Leader? Contemporary Issues in Education Research. 7(2) 145-149.

Marshall, S., Orrell, J., Cameron, A., Bosanquet, A., \& Thomas, S. (2011). Leading and managing learning and teaching in higher education. Higher Education Research \& Development. 30(2) 87-103.

McKee, A. \& Massimilian, D. (2006). Resonant leadership: A new kind of leadership for the digital age. Journal of Business Strategy. 27, 45-49.

Middlehurst, R. (2008). Not enough science or not enough learning? Exploring the gaps between leadership theory and practice. Higher Education Quarterly. 62, 322-339.

Nunn R. Pillay A. (2014). After invention of the h-index, is there a place for the teaching track in academic promotion? Higher Education Research \& Development. 33(4) 848-850.

Parrish, D. (2013). The relevance of emotional intelligence for leadership in a higher education context. Studies in Higher Education. doi: 10.1080/03075079.2013.842225

Pillay, A. (2013). Academic promotion and the $h$-index. Journal of the American Society for Information Science and Technology. 64(12) 2598-2599. 
Quinlan K.M. (2014). Leadership of teaching for student learning in higher education: what is needed? Higher Education Research \& Development. 33(1) 32-45.

Ramsden, P. (1998). Learning to lead in higher education. London, England: Routledge.

Raven, B. (1990). Political applications of the psychology of interpersonal influence and social power. Political Psychology. 11(3) 493-520.

Ruona W. (2005). Analyzing qualitative data. In R. Swanson \& E. Holton (Eds.), Research in organisations foundations and methods of inquiry (pp. 233-263). San Francisco, CA: Berrett-Koehler Publishers.

Sandelowski, M. (2010). What's in a name? Qualitative description revisited. Research in Nursing \& Health. 33(1) 77-84.

Schneider, Z., Whitehead, D., Lo-Biondo-Wood, G. \& Haber, J. (2013). Nursing and midwifery research (4th ed.). Chatswood, NSW: Mosby Elsevier.

Scott, G. Coates, H. \& Anderson, M. (2008). Learning leaders in times of change: Academic leadership capabilities for Australian higher education. Retrieved from http://www.acer.edu.au/documents/UWSACER CarrickLeadershipReport.pdf

Scott, G., Coates, H. \& Anderson, M. (2010). Australian higher education leaders in times of change: The role of Pro Vice-Chancellor and Deputy Vice-Chancellor. Journal of Higher Education Policy and Management. 32(4) 401-418. 